\title{
Seafloor habitat definition for spatial management in fisheries: a case study on the continental shelf of southeast Australia
}

\author{
Nicholas BAX*, Rudy KLOSER, Alan WILLIAMS, Karen GOWLETT-HOLMES, Tim RYAN \\ CSIRO Marine Research, Hobart, Tasmania, 7001, Australia
}

Revised 22 April 1999; accepted 27 April 1999

\begin{abstract}
The importance of habitat to fisheries production on Australia's southeast continental shelf is part of a five-year study of ecosystem functioning and its implications for a sustainable fishery. Benthic habitats from $40 \mathrm{~m}$ to $200 \mathrm{~m}$ were studied, based on identification of suitable sites from local fishers' information. Results presented here concentrate on data from a single mesohabitat at 40-60 m depth collected over two days. Macrohabitats within this mesohabitat were discriminated as soft, hard and rough from visual inspection of acoustic echograms. Subsequent analysis of the return echoes using roughness and hardness indices did not significantly improve real-time visual discriminations. Macrohabitats were sampled with an underwater video camera, sediment sampler, benthic sled, demersal trawl, gillnets and fish traps to relate the acoustic classifications to biological habitats. There were distinct differences in the benthic and fish communities between macrohabitats discriminated by acoustics. We concluded that discrimination of habitats from visual inspection of echograms, plus limited verification with physical sampling, could provide sufficient information for spatial management. However, successful management of individual species, the fish community and the ecosystem requires an understanding of the association of fishes with habitat at the macrohabitat and mesohabitat level, and its variability through time. (C) 1999 Ifremer / CNRS / IRD / Éditions scientifiques et médicales Elsevier SAS
\end{abstract}

seafloor habitat / acoustics / biological communities / underwater video / spatial management

Résumé - Définition de l'habitat benthique et gestion des pêches sur le plateau continental au sud-est de l'Australie. Le rôle de l'habitat dans la production des pêcheries est l'un des thèmes d'une étude consacrée pendant cinq années au fonctionnement dẹ l'écosystème et à ses implications pour une pêche durable sur le plateau continental du sud-est de l'Australie. Les habitats benthiques, entre 40 et $200 \mathrm{~m}$ de profondeur, ont été identifiés à partir des informations fournies par les pêcheurs locaux. Les résultals présentés ici sunt issus de données collectées en $2 \mathrm{j}$ sur un seul mésohabitat, entre 40 et $60 \mathrm{~m}$ de profondeur. Les macrohabitats intérieurs à ce mésohabitat ont été classés en meubles, durs et rugueux par examen visuel et échogrammes acoustiques. L'analyse ultérieure des échos selon les indices de rugosité et de dureté n'apporte pas d'amélioration significative aux classifications visuelles en temps réel. Les macrohabitats ont été échantillonnés en utilisant une caméra vidéo sous-marine, un carottier à sédiments, un traîneau benthique, un chalut démersal, des filets maillants et des nasses à poissons afin d'associer les classifications acoustiques aux habitats biologiques. Des différences entre les macrohabitats ont été trouvées par acoustique dans les communautés benthiques et pélagiques. En conclusion, la discrimination des habitats par l'examen visuel des échogrammes et un contrôle limité avec prélèvement physique, pourraient apporter une information suffisante à la gestion spatiale. Cependant, une bonne gestion des espèces particulières, de la communauté des poissons et de l'écosystème exige de comprendre le lien entre les poissons et l'habitat à l'échelle du macrohabitat et du mésohabitat, et sa variabilité temporelle. C 1999 Ifremer / CNRS / IRD / Éditions scientifiques et médicales Elsevier SAS

habitat benthique / acoustique / communauté biologique / vidéo sous-marine / gestion spatiale

* Correspondence and reprints: Nicholas.bax@marine.csiro.au 


\section{INTRODUCTION}

Successful management of marine fisheries is widely recognised as requiring understanding of the interactions of one species with another and the environment in which they live. The difficulty in incorporating species and environment interactions in marine fisheries management has been the large amount of data required to understand those interactions and a lack of predictability [35, see also 12, 17]. However, one way in which fish interact with their environment is through their use of habitat. Fishers use their knowledge of habitat to target their fishing effort and the non-random, small-scale spatial distribution of their effort indicates the importance of this environmental interaction. Where the targeted habitat is seafloor habitat that may be impacted by fishing, there is a need to manage habitat use because technological aids permit fishers to exploit fishes in habitats that were previously inaccessible [eg. 10]. For example, geographical positioning systems (GPS) have enabled fishers to fish closer to obstructions that have previously limited the use of mobile gear such as trawls. Habitats that are associated with high fish abundance can be targeted and repeatedly fished, increasing effective fishing effort and impacts on the fish stocks and the habitat. Further, the development of "environmentally-friendly" gear, such as trawls with roller gear and high ground ropes, enables fishers to trawl an increasing proportion of the seafloor, because environmentally-friendly gear is less likely to be fouled or damaged on rough ground. These factors all lead to an increasing proportion of habitat being accessible to mobile gear such as trawls that have been shown to directly alter habitat $[19,28,33]$. Unfishable habitat that once provided technological no-take reserves - a level of insurance against ill-informed management practices and perhaps spawning refugia - is being reduced. To quote [26]:

"...what fisheries management desperately needs is to confront uncertainty directly by building 'insurance' into management plans. Managers have lost credibility with the public because their approaches don't incorporate safety factors. Marine reserves represent one of the most effective ways for providing such a safety factor, thereby integrating the precautionary principle into fisheries management".

In fact, unless current technological no-take reserves are replaced by management no-take (or limited use) rescrves, ovcrall fishing impacts on habitat will incrcasc and the level of insurance will decrease. Additional management measures are now necessary just to maintain the status quo.

The CSIRO Marine Research is conducting a 5-year study of the role of habitat in fisheries production on the southeast Australian shelf. The study aims to determine the potential of spatial management as a supplement to the current single-species management of marine fisheries in this area [5]. The study area is the southeast continental shelf area of the South East Fishery - Australia's most important fishery for domestic scalefish markets [30]. This area of continental shelf has been trawled since the early 1900s. Fishing effort continues to increase, despite various management interventions, for example, reported trawling hours in the study area have increased $25 \%$ since 1985 [5 and Bax, unpublished data]. A nontrawl sector of the fishery targets many of the same species as the trawl using dropline, demersal longline, gillnets and traps. The non-trawl sector targets distinct habitat features (detected on echosounders) and is concerned that increased effort and targeting by the trawl sector on distinct habitat features will modify the habitat and reduce future availability of fish.

In this paper we present the techniques that we have used to identify and map different habitat types and their relationship to invertcbratc and fish communities. Data are presented for one mesohabitat (an area measured in $\mathrm{km}$ and defined by physiography and depth, [15]) within the megahabitat (an area measured in $100 \mathrm{~s}$ of $\mathrm{km}$ defined by oceanography and proximity to seafloor, [15]) of the southeast Australian shelf. Results for other mesohabitats and their integration as the southeast Australian shelf megahabitat are referred to in this paper but will be presented elsewhere. How we define habitat determines the questions we ask and therefore the description of the environment that results. For the purposes of this study, and following [18], we define habitat as "simply the place where an organism lives".

The scientific data presented in this paper were collected over two days on CSIRO's 67-m research vessel 'Southern Surveyor' and two days fishing from a small commercial fishing vessel. Our goal in this paper is to describe a data collection system of increasing complexity that can be used to define habitat and habitat use. We hope that readers will evaluate this system against their own objectives and determine the minimum level of sophistication in data collection that they require. There is often, in our opinion, an excess of technology and expense used to provide answers to relativcly simple management questions. 


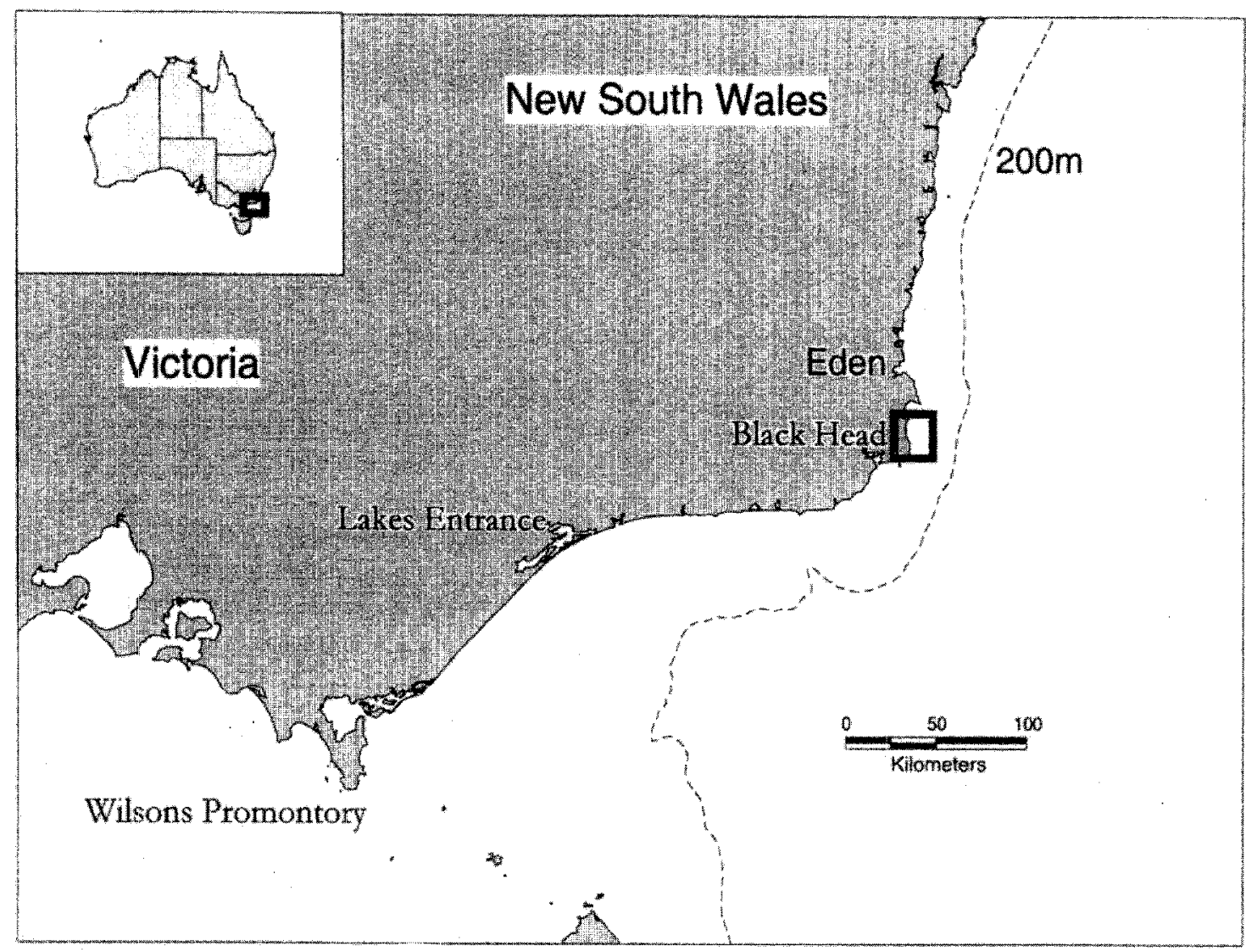

Figure 1. Southeast $\Lambda$ ustralja continental shelf and study arca.

\section{MATERIAL AND METHODS}

\subsection{Study area}

The southeast Australian continental shelf between the latitudes of $36^{\circ}$ and $39^{\circ} \mathrm{S}$ is the focus of the five year study (figure 1 ). The shelf extends to $170-200 \mathrm{~m}$ depth and is $25 \mathrm{~km}$ wide in the north of the study area and over $175 \mathrm{~km}$ wide in the south. Riverine input is minimal. Oceanography is complex and leads to intrusions of continental slope water onto the shelf especially during summer upwellings [11,31]. Seafloor habitat is a function of geology and hydrography. Outcrops of continental basement rock form outcrops near the coast, while coarsegrained sandstone clominated by quartz extends along the inner shelf (parallel to the palaeo-shoreline) and is consistent with sand bodies formed in a high energy coastal plain environment. On the outer shelf, fossiliferous limestone consisting largely of bivalve and bryozoan clasts are common [4 and unpublished data]. These seafloor features occur in a high energy environment where tidal currents are the dominant driving force (off eastern Victoria), and waves in the area average $1-3 \mathrm{~m}$ in height and penetrate to the seafloor in $60 \mathrm{~m}$ depth [21].

For the purposes of this study, these characteristics meant that equipment was required that could be used in poor sea conditions, in an area of strong currents. Further, photographic equipment would have to be able to traverse areas of loose sediment and reef while maintaining close contact with the seafloor due to the low visibility.

The data presented in this paper concentrate on the Black Head mesohabitat (figure 1). Where necessary, and especially for the analysis of fish distribution, data from the adjacent Disaster Bay habitat were used to improve the analysis.

\subsection{Fishers' data}

At the start of this project we spent considcrable effort in developing sound working relationships with key fishers 
of our study area. Once a level of trust had been established, the fishers generously provided us advice and their personal charts (on paper and electronic media) detailing their observations on habitat and habitatfish associations that they had collected over many years fishing.

A map of their observations enabled us to identify seven mesohabitats with significant topographic heterogeneity to survey. Our results from 'Black Head' - the first mesohabitat to be surveyed - are presented here.

\subsection{Acoustic survey of 'Black Head' mesohabitat}

Two acoustic transects were run along the 40 and $60 \mathrm{~m}$ depth contours with a Simrad EK-500 scientific sounder operating at 12,38 and $120 \mathrm{kHz}$. Only data from the $120 \mathrm{kHz}$ sounder are presented here because they provided better visual discrimination at 40-60 $\mathrm{m}$ depth than the 12 or $38 \mathrm{kHz}$ frequencies. 'The $120 \mathrm{kHz}$ sounder had a $10^{\circ}$ conical beam and was operated at a $1 \mathrm{~ms}$ pulse length throughout the survey. Echograms were displayed and recorded after correction of one-way beam spreading and two-way sound absorption losses on a colour paper chart recorder and recorded digitally with a timestamp and GPS position. Visual discrimination of bottom type was based on the length and intensity of the tail of the first echo and the intensity of the first and second echoes $[6,24]$. This provided sufficient information to divide the mesohabitat into three macrohabitats. The macrohahitats were:

- Soft habitat - short tail on first ccho, low signal strength on first and second echoes;

- Hard habitat - short tail on first echo, high signal strength on first and second echoes;

- Rough habitat - long tail on first echo, moderate to high signal strength on first and second echoes.

We adopted this approach mindful that acoustic scattering gives only an indirect indication of sedimentary bottom particle size [32]. The detailed acoustic scattering from geological seabed properties is a complex subject, and it is not clear to what extent acoustic scattering from the seabed is a useful measure of seabed properties important in determining biological assemblages, especially over a range of habitat types and depths. One of the aims of this project was to determine whether these simple acoustic indices of macrohabitat type were robust over a wide range of mesohabitats and could be uscd in broadscale mapping.
The EK-500 used has a wide dynamic range in comparison with commercially available acoustic bottom profilers $-160 \mathrm{~dB}$ - and is able to record ping data digitally. Its wide dynamic range enables echoes to be recorded from weak, above-seabed features including fish and macrobenthos as well as the whole of the strong seabed echo. It thus provides a high level of information compared to typical commercially available acoustic bottom profilers, eg. RoxAnn [6], which was also attached to the $120 \mathrm{kHz}$ echo sounder to determine its performance.

The stored digital data were analysed after the survey to determine bias in habitat discrimination due to ship direction, ship speed and depth. Two descriptors of the return echo that corresponded with the visual discriminators used for the echograms and related to the RoxAnn system $[6,24]$ were chosen. The first descriptor (E1) is an integration of the tail of the first bottom echo, where the energy in the tail is assumed to derive from scattered reflections that increase in rough habilat. We defined the tail as between 5 and $15 \mathrm{~m}$ at $50 \mathrm{~m}$ water depth after the detection of the seabed echo as this gave the best diserimination in this study. It is important to note that this may represent acoustic contributions off the normal axis of the beam from 22.8-39.7 degrees for the $1 \mathrm{~ms}$ pulse due to the expanding spherical wave front. The second descriptor (E2) is an integration of the entire second bottom echo and provides a measure of the total seabed energy. The second reflection theoretically has added discrimination over the energy of the first echo as it has been doubly reflected from the seabed squaring the reflection coeffcient and improving discrimination power [6]. The two indices (E1 and E2) were plotted as a scatterplot and boxes drawn around clusters of points, defined by a knowledge of the physical meaning of the E1 and E2 values. These boxes then define the different bottom types. This subjective technique is a standard approach used in delineation of RoxAnn data, and has been shown to be relatively robust compared with unsupervised cluster analysis, though prone to lower consistency between surveys [16].

Habitat delineations from this post hoc analysis of the stored digital data were then compared with habitat delineations derived in real time from visual examination of the echograms. The two indices were depth-corrected over the depth range $40-60 \mathrm{~m}$ by adjusting for sound absorption and one way spherical spreading losses and E1 was further standardised by ensuring that a similar off-axis angular section was integrated by shifting the depth range of the tail integration according to depth. The 
E1 and E2 indices were mapped using Vertical Mapper in Mapinfo (rectangular interpolation, cell size $0.005^{\circ}$, search radius $0.01^{\circ}$ ). Because we did not have EK-500 data coincident with trap and gillnet sets (deployed from a small commercial fishing boat), sample transects for all gear types were overlaid on the contour maps, the corresponding cross-section taken and the mean of E1 and $\mathrm{E} 2$ recorded for each transect.

\subsection{Video survey of Black Head macrohabitats}

The three macrohabitats were surveyed with a video camera towed behind a 100-kg downweight suspended from the research vessel [3]. The downweight was used to eliminate pitch from the research vessel and enabled surveys to be carried out in 5-m seas. A positively bouyant platform trailing from the downweight was kept in contact with bottom habitats from soft sand to rough reef by a length of chain that dragged along the bottom [3]. The platform supported a remotely viewed colour video camera on pan and tilt head, an in situ video camera, a $35 \mathrm{~mm}$ Photosea 1000 still camera with flash, two parallel lasers for sizing objects and $1000 \mathrm{~W}$ of tungsten lamps for illumination. An acoustic sensor on the downweight provided advance notice of dropoffs or cliffs that would require the winch operator to alter the wire out.

\subsection{Survey of invertebrates from Black Head macro- habitats}

Epifauna and infauna were collected with a 0.65-ton, 2.9-m wide sled divided into two sides - an epifaunal side with a length of heavy chain suspended cross-wise beneath a cage of $10-\mathrm{mm}$ anodized steel mesh, and an infaunal side with a $8.5-\mathrm{cm}$ wide plough extending $10 \mathrm{~cm}$ below a similar mesh cage at an angle of $32^{\circ}$. The sled was towed at $1 \mathrm{~m} / \mathrm{s}$ for $20 \mathrm{~min}$ and invertebrates extracted by either the chain or plough were filtered by the water flow though the steel mesh cages. Individuals or pieces that did not pass through the steel mesh were collected in two $2.5-\mathrm{cm}$ stretched mesh codends.

The in- and epifauna catches were highly diverse and contained many taxa which have not been described. To simplify processing and to ensure that all catches were processed on board, a functional taxonomic approach was developed. Samples were subsampled as necessary and sorted to major taxa. A major taxon could be a phylum (eg. Porifera, Bryozoa), class (eg. Ascidiacea), or a species for the better known organisms (eg. within Mol- lusca). Where the major taxon was higher than species, it was usually divided further based on its functional characteristics that were expected to be related to habitat type (eg. Bryozoa were divided into soft, fenestrate and massive). Representative specimens of each taxonomic or functional unit were photographed and an identification key made to ensure consistent taxonomic classification throughout the study.

\subsection{Survey of fishes from Black Head macrohabitats}

Three types of fishing gear- trawl, gillnet and trap were used to sample the rangc of habitat typcs targeted in our study. In brief, the commercial fish trawl net had a mouth opening of $\sim 2.5 \mathrm{~m} \times 20 \mathrm{~m}$, and mesh sizes ranging from $230 \mathrm{~mm}$ in the wings to $40 \mathrm{~mm}$ in the codend. It was fished from twin warps with $50 \mathrm{~m}$ sweeps. Traps were $1.8 \times 1.5 \times 1.2 \mathrm{~m}$ in size, with wood frames and $5-\mathrm{cm}$ galvanised wire mesh walls with a $300 \times$ $50 \mathrm{~mm}$ slot, single-funnel entrance. The gillnet consisted of two fleets of six 90-m long panels of different mesh sizes $(50,76,100,125,150$ and $175 \mathrm{~mm})$ separated by $40 \mathrm{~m}$ gaps. The gillnet was weighted with $38 \mathrm{~kg}$ of lead on the footrope per panel, floated with $11.4 \mathrm{~kg}$ bouyancy on the headline per panel, and had a total length of $\sim 1.5 \mathrm{~km}$.

The trawl was deployed from the research vessel for 30 min tows but only in the soft and hard macrohabitats. The gillnet and traps were fished in all habitats from a commercial fishing vessel immediately after the research vessel survey. Each gear was fished twice during the day and twice at night in each macrohabitat.

Fish caught by all gears were sorted to species, weighed and counted; all species represented by more than five individuals were measured, and a selection of species were retained for morphometric analysis in the laboratory. These data will permit us to examine the association of fish species, size classes and morphotypes with habitat types, however, in this paper we present only an overview of fish assemblage structure associated with the Black Head and adjacent Disaster Bay macrohabitats.

\subsection{Ancillary data}

The following data have been collected to assist interpretation of the results of this study:

- sediment samples collected in a stainless steel box, situated over a $50-\mathrm{mm}$ wide by 120 -mm long opening on one sled skid. The opening has a bevelled leading edge and 
was closed with a rubber flap hinged at the front to prevent winnowing of sediments during retrieval. These samples are being processed for grain size (a key physical characteristic), and the composition of photoreactive pigments, breakdown products and stable isotopes of carbon and nitrogen (to determine pathways of primary production);

- fish stomach contents to determine whether diet changes for the same fish species in different macrohabitats; and

- oceanography (conductivity, temperature, fluorescence and chemistry) to determine the influence of macrohabitat topography on water flow and productivity.

\subsection{Data analysis}

All data were entered onboard into a dedicated Oracle database, except for the acoustic data which were collected in a specifically designed database - ECHO [34] and fish data on the commercial fishing vessel which were entered into an EXCEL spreadsheet onboard and transferred into the Oracle database on return. At the end of the survey we left the vessel with a complete dataset, requiring only error checking before analysis.

Data analysis is ongoing with only the preliminary analyses presented in this paper. Acoustic data have been processed with the ECHO software. Invertebrate data were analysed only to the level of which taxa or functional groups appeared in one habitat but not other habitats. Multivariate analysis of fish distributions was used to examine assemblage structure in relation to macro- and mesohabitats. Catch data were standardised to unit time for each gear separately and pooled to provide a mean catch rate by gear by macrohabitat. Mean catch rates were analysed using modules of the PRIMER program [7]: CLUSTER (hierarchical agglomerative clustering) was used to form groups of samples (macrohabitats) based on between-sample similarities, MDS (non-metric multidimensional scaling) used to display between-sample similarities in 2-dimensional (2-d) space, and SIMPER used to identify species making the greatest contribution to the dissimilarity between macrohabitat groups. The Bray-Curtis similarity index was used in all analyses following double square root transforma-

A)

B)

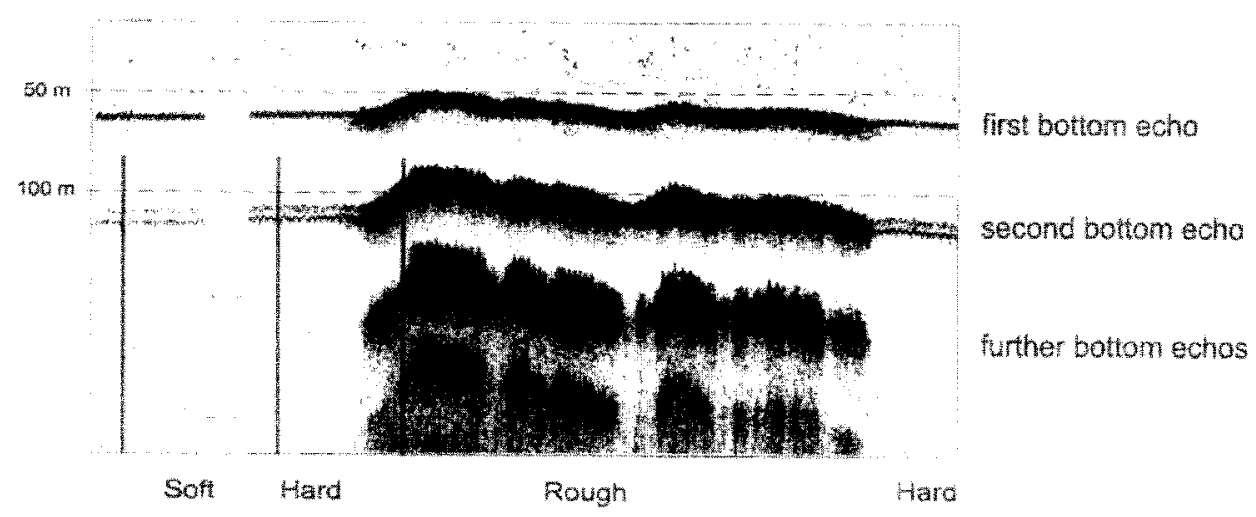

c)

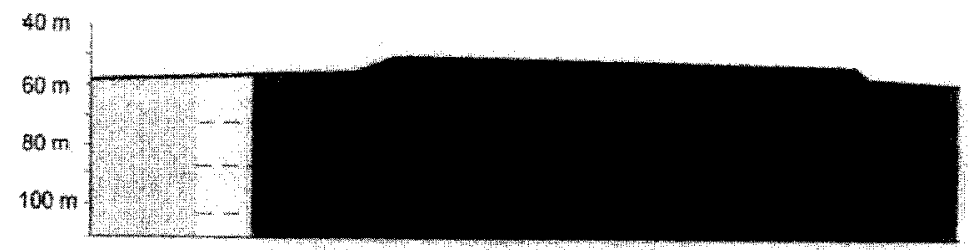

RoxAnn classification

Figure 2. Habitat delineation of the Black Head mesohabitats along one transect, showing A) the echogram, B) qualitative classifications made during acoustic transecting, and C) a posterior classification using "RoxAnn-type", hardness and roughness clusters from figure 4. The echogram has been processed to maximise visual discrimination between soft and hard mesohabitats based on intensity of the second bottom echo. "RoxAnn-type" indices discriminate soft from hard bottom based on the total energy of the second bottom echo and discriminate hard from rough bottom based on the acoustic backscatter in the tail of the first bottom echo. 
tion of the data that minimised the stress of MDS plots and stabilised the variance of the abundance data. Analysis of video data is ongoing and is not presented here.

\section{RESULTS}

\subsection{Acoustic Survey}

Visual interpretation of the echograms (figure 2A) delineated the three mesohabitat types along the acoustic transect (figure 2B). This provided the basis for subsequent sampling. The two acoustic transects along the 40 and $60 \mathrm{~m}$ depth contours were supplemented by further acoustic data collected during and between other sample collection. These data were processed subsequent to the survey.

\subsubsection{Comparison of acoustic hard and rough seabed indicators with visual examination of echograms}

The two habitat indicators - E1 and E2, or rough and hard respectively - were computed from the stored digital data and plotted. The data were divided subjectively into four groups on the scatter plot (figure 3), plotted (figure $2 \mathrm{C}$ ) and then compared with the categories determincd visually from the cchogram (figure $2 \mathrm{~B}$ ). Therc was effectively a one to one correspondence between habitats determined by the two methods.

The discrimination between hard and soft habitats represented in an echogram can be hard to reproduce in a document - the average difference in back scattering energy of the second bottom echo in hard and soft habitats in this example is only $1.3 \mathrm{~dB}$, while the range in back scattering energy received is $80 \mathrm{~dB}$, and $\mathrm{dB}$ is a log scale. The

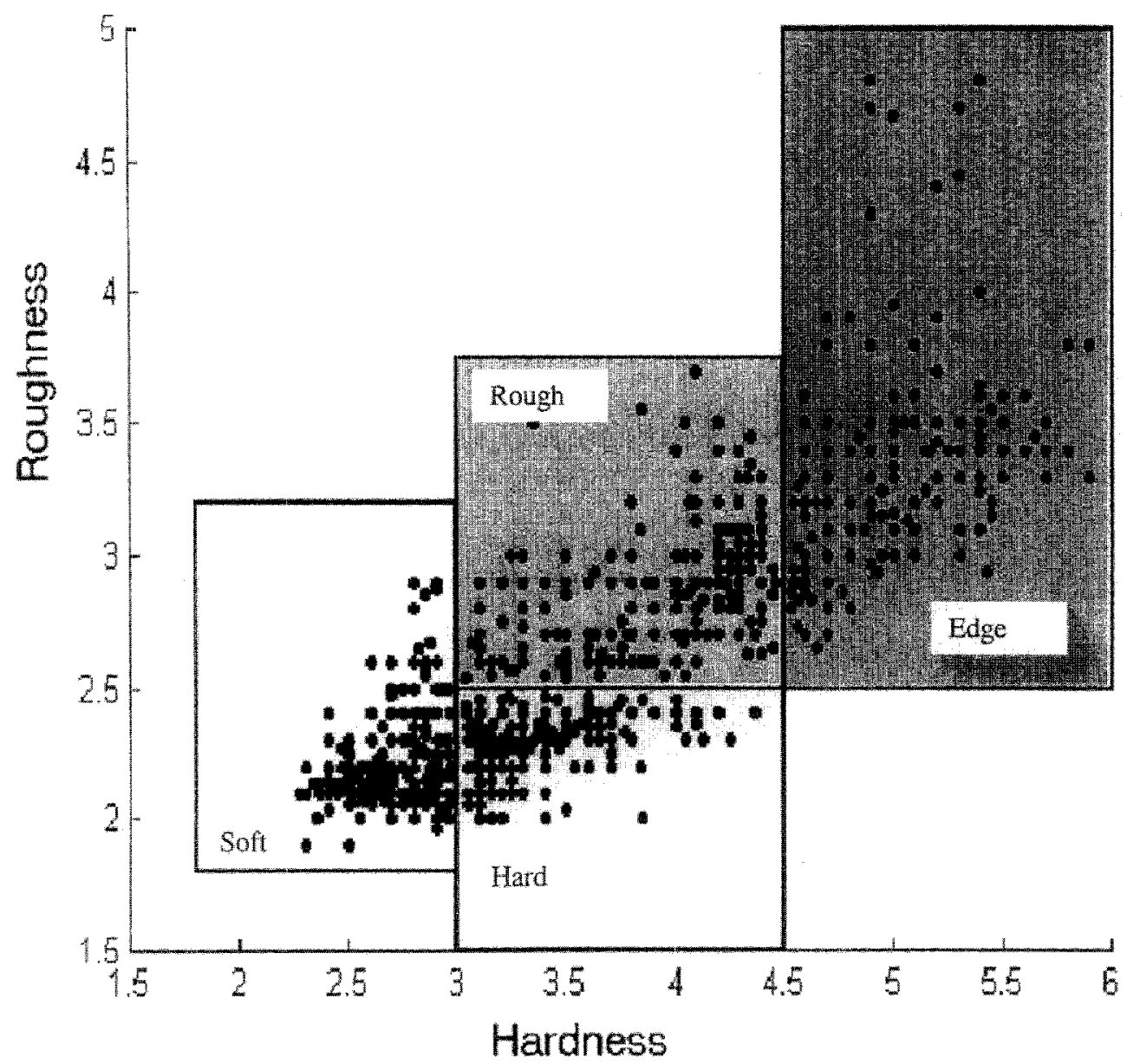

Figure 3. Scatterplot of "RoxAnn-type" roughness (E1) and hardness (E2) indicators and division of paired indices space into habitat types. Division of paired indices was arbitary, but this method has some experimental justification [16]. 


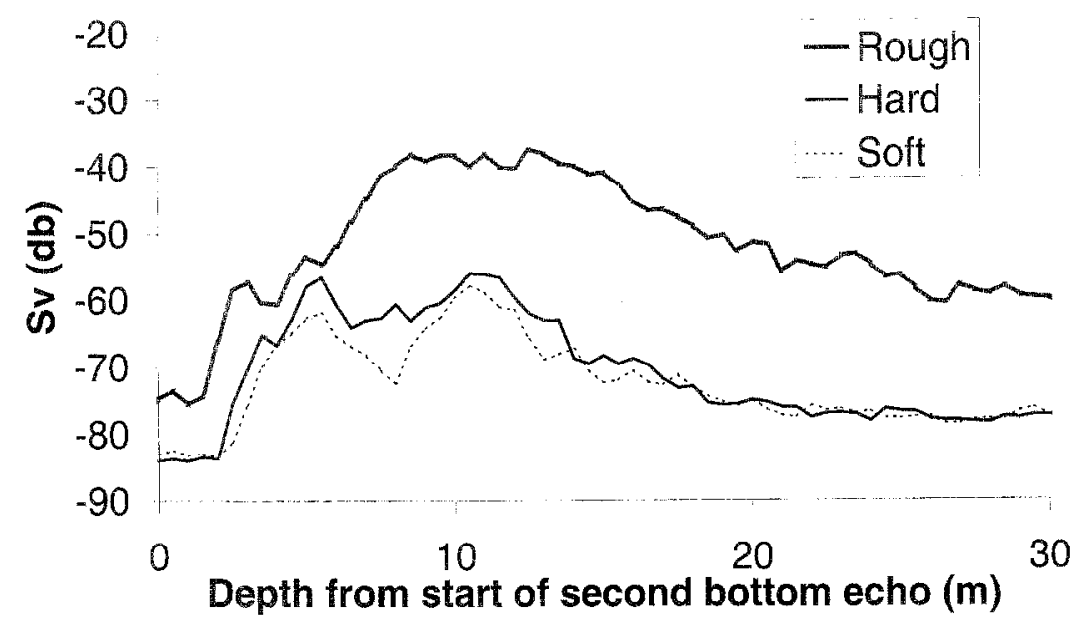

Figure 4. Average acoustic back scattering energy of the second bottom echo from ten pings in the soft, hard and rough habitats of figure 2. The samples are shown by the narrow vertical lines across the second bottom echo in that figure.

difference can be better appreciated by plotting the average back scattcring cnergy for the second bottom ccho only (figure 4).

There was also a strong correlation between E1 and E2 (figure 3), indicating considerable overlap in the acoustic properties of the two indices. The longer length of the tail of the first bottom echo that is used as an indicator of rough habitat (E1), also results in a longer tail of the second bottom echo (figure 4). As the entire second bottom echo is used to estimate hardness (E2), it is not surprising that the two indices are correlated.

\subsubsection{Operating conditions and the acoustic hard and rough indicators}

Acoustic data from the megahabitat (25 to $200 \mathrm{~m}$ ) have been analysed to determine possible impacts of operating conditions on E1 and E2. No effects of ship direction, ship speed (up to 12 knots depending on weather), ship track (straight or curved) were found (Kloser unpublished data). There was linear correlation of both E1 and E2 with depth. It was necessary to correct the data for even the narrow depth range within mesohabitat (eg. 40-60 m) by adjusting for sound absorption and one-way spherical spreading losses. E1 was further standardised by shifting the depth range of the tail integration according to depth to cnsure that a similar off axis angular section was integrated regardless of bottom depth.

Acoustic data collected from the $120 \mathrm{kHz}$ transducer with a RoxAnn bottom-typing package were analysed to determine depth dependency of the E1 and E2 indices. Both indices increased markedly with depth. The roughness index (E1) reached a maximum at $130 \mathrm{~m}$ - all bottom types at depths beyond this werc given the maximum E1 value. The hardness indicator $(\mathrm{E} 2)$ reached a maximum at $70 \mathrm{~m}$. Thus the depth corrections applied to the EK-500 data to account for the natural properties of acoustic wave propagation in aquatic environments were not applied within the RoxAnn package tested. A correction for this depth correlation either by equipment setup during data collection or by post processing of data is required if these data are to provide comparison of habitat types over a wide depth range. No useful data can be retrieved once the maximum has occurred.

\subsubsection{Relationship of habitats defined by acoustics to habitats defined by fishers}

Maps of hardness and roughness from the stored acoustic data overlaid on the fishers' observations for the Black Head and adjacent Disaster Bay mesohabitats generally showed a good level of correspondence (figure 5). All features described by the fishers were present, but fine scale detail was not always accurate. A failing of the acoustic maps of hardness and roughness is illustrated by the elongate lines of 'finger reef' (as reported by fishers) at the top of the plots, that do not match up with the 'patchy reef' detected as acoustic hardness and roughness. A video survey of the area showed that the gutters between the finger reefs were filled with gravel patches and these returned a more intense signal than the sediment-covercd recf and were interpreted initially as patchy reef. 

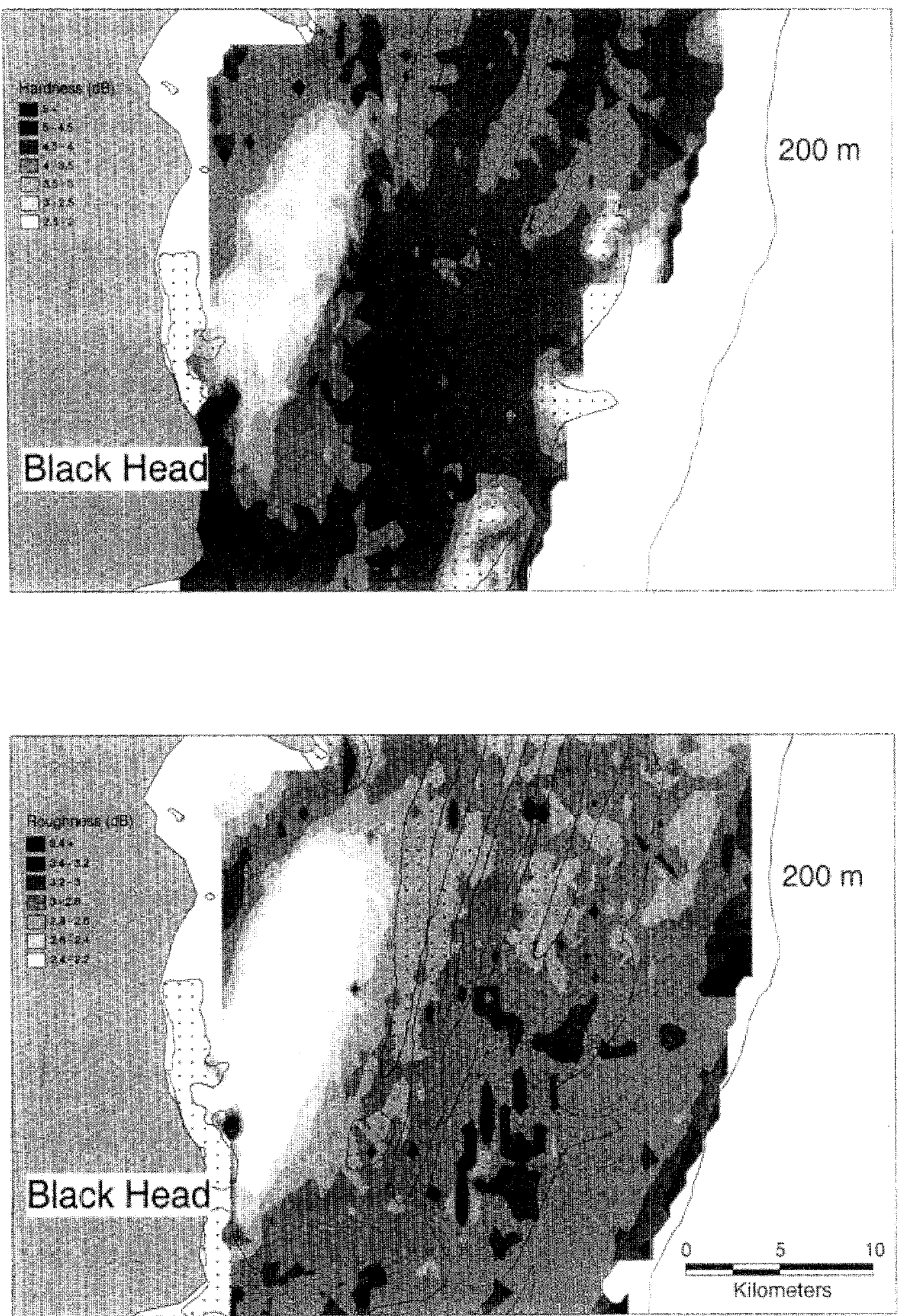

Figure 5. Acoustically-defined hardness (top) and roughness (bottom) indices with fishers' observations of hard and rough areas overlaid. 

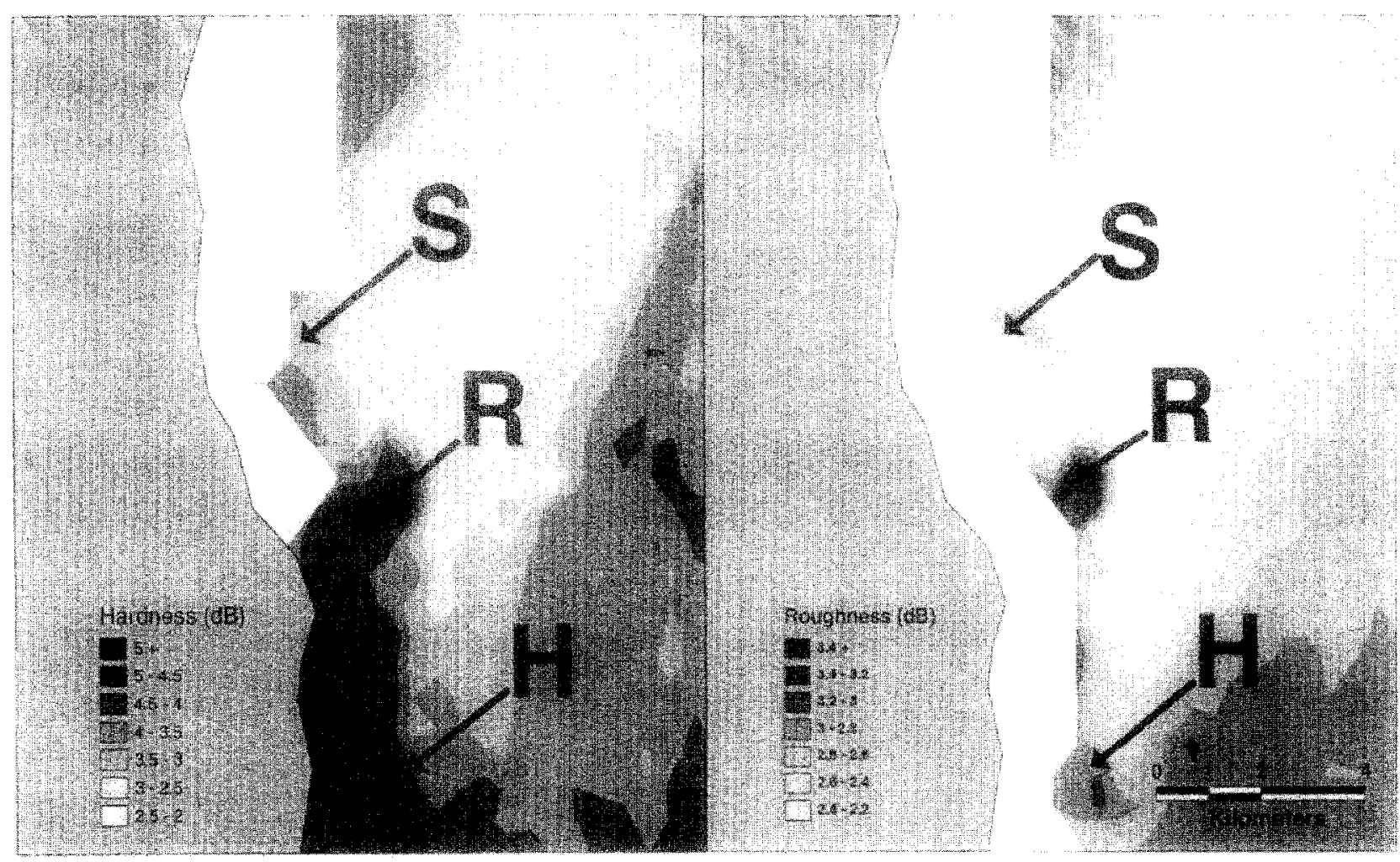

Figure 6. Locations of soft (S), hard (H), and rough (R) sampling sites.

Locations of benthic sled, trawl, gillnet and trap transects (figure 6) were overlaid on the contoured roughness and hardness indices and average roughness and hardness for each transect determined (table $D$ ). There is a gradual increase in roughness and hardness with our visuallydetermined habitat delineations of 'soft', 'hard' and 'rough'. The lower value of hardness for the gillnet transect in the rough compared to the hard macrohabitat, may be due to increased scattering, and therefore decreased normal reflection, of acoustic energy in rough habitats.

Table I. Mean roughiness and hardness indice; for biological sam pling transects at Black Head.

\begin{tabular}{lcccc}
\hline & & \multicolumn{3}{c}{ Macrohabitat } \\
\cline { 3 - 5 } & Gear & Soft & Hard & Rough \\
\hline Hardness & Trawl & 2.80 & 3.50 & \\
& Gillnet & 3.20 & 4.50 & 4.20 \\
& Traps & 3.60 & 4.00 & 4.50 \\
Roughness & Trawl & 2.20 & 2.50 & \\
& Gillnet & 2.20 & 2.90 & 2.90 \\
& Traps & 2.10 & 2.80 & 3.00 \\
\hline
\end{tabular}

\subsection{Biological sampling}

Habitats defined by acoustics, though consistent and seemingly realistic, are of little significance to biology (or fisheries management) if they are not related to the distribution of organisms. The three macrohabitats defined by real-ime observation of the EK-500 echograms were viewed with the towed video system and sampled for invertebrates and fish.

\subsubsection{Video observations}

Video transects took place on the soft, hard and rough macrohabitats (figure 6). The soft habitat comprised a muddy or sandy bottom with little attached macrofauna. The hard macrohabitat indicated a harder bottom again with little attached macrofauna. The rough macrohabitat was a raised slab habitat with diverse macrofaunal cover and associated fish schools.

\subsubsection{Invertebrate communities}

Invertebrates showed distinct gradation between habitai types (table II). In soft macrohabitats, sponge, bryozoan 
Table II. Invertebrate taxa and functional categories unique to macrohabitat at Black Head.

\begin{tabular}{lccc}
\hline $\begin{array}{l}\text { Taxonomic } \\
\text { category }\end{array}$ & Soft & Hard & Rough \\
\hline Sponge & Low & Branching & $\begin{array}{c}\text { Encrusting } \\
\text { Bushy } \\
\text { Lumpy } \\
\text { Massive }\end{array}$ \\
Bryozoans & Soft & $\begin{array}{c}\text { Soft } \\
\text { Fenestrate }\end{array}$ & Massive \\
Ascidians & Solitary & Solitary & Compound \\
Other & $\begin{array}{c}\text { Polychaetes } \\
\text { Gastropods } \\
\text { Bivalves }\end{array}$ & $\begin{array}{c}\text { Ophiuroids } \\
\text { Solitary coral } \\
\text { Echinoderms }\end{array}$ & \\
& Echinoderms & & \\
& &
\end{tabular}

and ascidian functional forms were soft and flexible and only insubstantially anchored to the substrate or rounded and unattached to the substrate (figure 7). As the macrohabitat changed to hard and then to rough, sponges and bryozoan forms were firmer and denser, requiring the solid anchor points found on the buried or exposed rock in these macrohabitats. Several taxa sampled in soft macrohabitat (polychaetes, gastropods, bivalves) were not present in the samples from hard and rough macrohabitat. Ophiuroids and solitary coral were only found in the samples from the hard macrohabitat.

Changes in functional types between macrohabitats were very noticeable. In one instance where the invertebrate sample contained a mix of forms expected in soft anld hard macrohabitats, we repeated the acoustic survey at higher coverage, and found the area that wc had thought to be a soft macrohabitat was indeed a mix of soft and hard macrohabitat. The soft macrohabitat was resampled.

\subsubsection{Fish communities}

A comparison of the relative selectivity and catch rates of the trawl, gillnet and traps showed that over all mesohabitats, the trawl caught most species (113 of a total 143), and the gillnet more than double the number caught by trap (91 vs 39). Twenty three species were taken by all three gears whereas 64 species $(45 \%)$ were caught by only one -46 by trawl, 14 by gillnet and four by trap. There was little overlap between the species that delineated the common inner and outer shelf macrohabitats in gillnet and trawl calches. Only one of 19 species contributing most importantly to the dissimilarity was common
FUNCTIONAL TYPE

MACROHABITAT AFFINITY

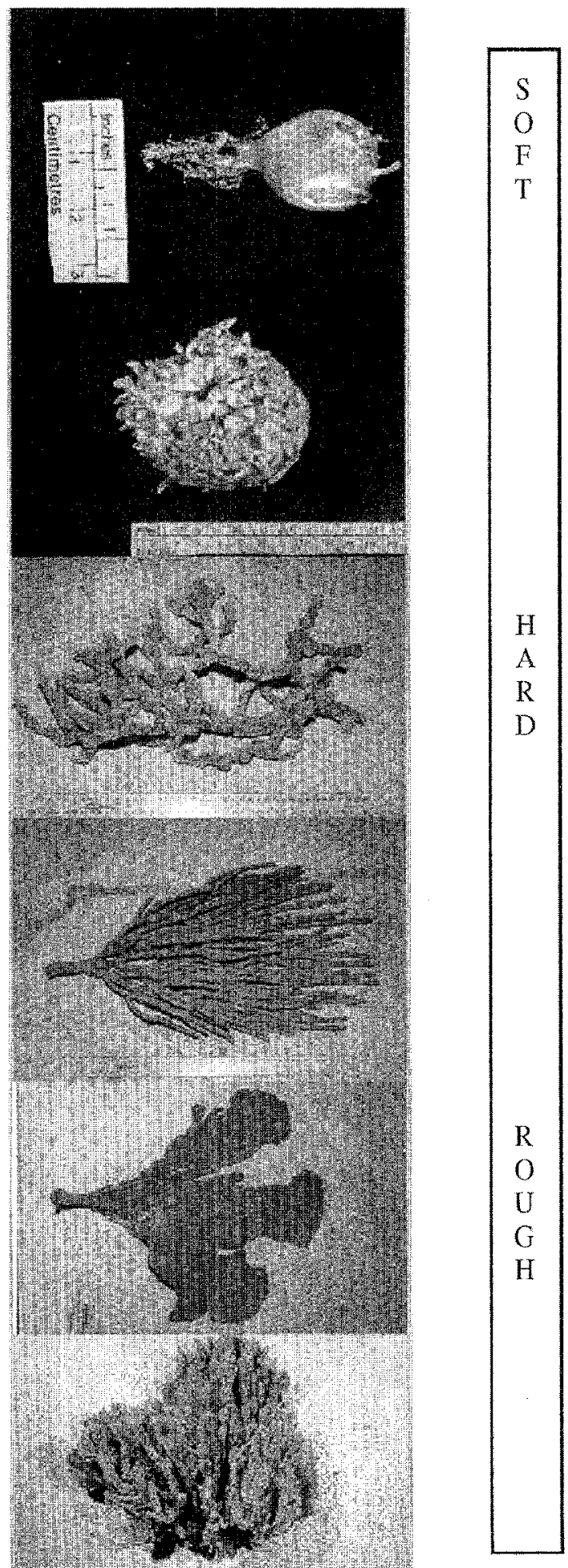

Figure 7. Functional types of sponge unique to Black Head macrohabitats. 
All sites

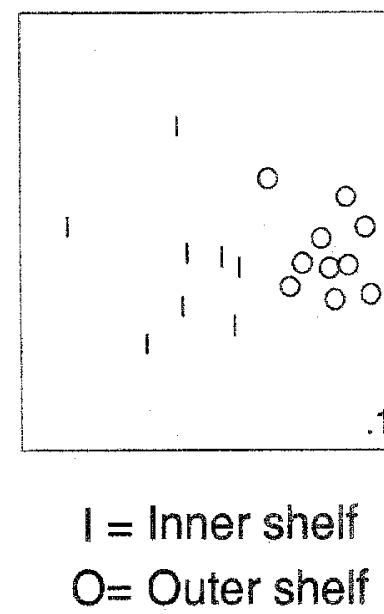

inner shelf
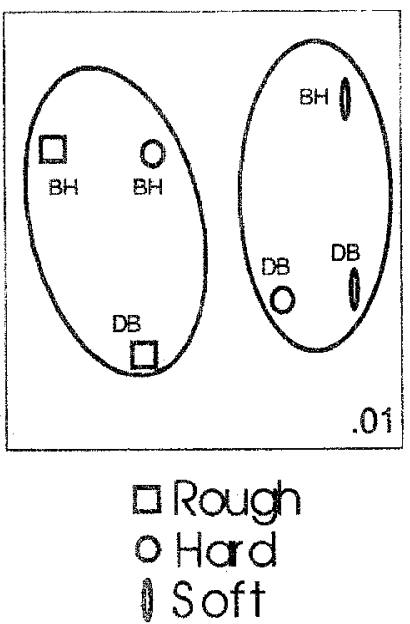

Black Head

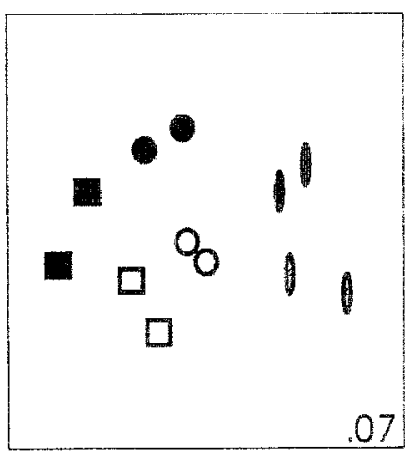

Figure 8. Grouping of Black Head macrohabitats in 2-d MDS plots based on fish biomass data illustrating mesohabitat, macrohabitat and diel effects; (a) delineation of inner and outer shelf, (b) delineation of macrohabitats at Black Head (BH) and the adjacent Disaster Bay (DB) mesohabitat based on habitat type (circles correspond to grouping in cluster analysis), (c) diel changes at Black Head.

to gillnet and trawl catches. Such a difference in species composition indicated both the high degree of difference in the selectivity of each gear, and the robustness of the inner and outer shelf grouping. The gillnet proved to be the most effective sampler overall because it could be deployed on all bottom types.

Multivariate analysis of biomass data showed a high correspondence of community distribution patterns across habitat types in trawl and gillnet catches despite different suites of species being caught by each gear (Williams, unpublished data). For these reasons, only data from gillnet catches are presented in this paper. Fish community composition at the mesohabitat scale was influenced primarily by depth (figure 8a), and also dominant water mass, proximity to vertical relief and proximity to the shelf break (Williams, unpublished data). With these factors removed in an analysis restricted to the inner shelf Black Head and adjacent Disaster Bay mesohabitats (figure $8 \mathrm{~b}$ ), fish communities show a delineation of macrohabitats corresponding to the bottom characterisation defined by acoustics (table I and figure 6 ). The distributions of fish indicated a strong association of the hard macrohabitat at Black Head with rough macrohabitats, whereas the adjacent hard Disaster Bay samples grouped with soft macrohabitats. Diel changes in fish community composition were also evident over each macrohabitat type at Black Head (figure $8 \mathrm{c}$ ), indicating either a variablc catchability (availability and/or vulnerability) of some species, or diel movement between habitat types.
The ten species contributing most to the dissimilarity between the groups of Black Head and Disaster Bay macrohabitats (figure 8b) are shown in table III. Most of the discriminating species were common to both but occurred at markedly different abundances. Only two species, tiger flathead and red cod, occurred only on one bottom type (soft), although two species associated with rough bottom (butterfly perch and bastard trumpeter) were scarce on soft bottom.

\section{DISCUSSION}

Ecological processes are intrinsically linked with the underlying physical scales of the ecosystem and are therefore scale-dependent. Definition of an ecologically significant spatial scale at which to map habitat features over large regions of the continental shelf is a prerequisite to spatial management based on habitat [1]. Further, if spatial management is to be successful, it must be of a scale that is conducive to effective monitoring and enforcement by management agencies.

Spatiai management of the marine resources of the southeast Australian continental shelf has been proposed by several groups and government agencies for conservation purposes. However, there has been little information on the biological resources of the shelf that can be used to evaluate the likely success of spatial management in this area. Our 5-year study of the continental shelf, of which 
the data in this paper are part, is focused on providing the scientific information and methodology necessary for this evaluation. In our study of continental shelf habitat, we have directed surveys at the scale of mega- meso-, macroand microhabitat (i.e. from $100 \mathrm{~s}$ of $\mathrm{kms}$ to $\mathrm{cms}$ ) to provide an overview of the spatial organisation of habitat. In this paper we have presented the results from three macrohabitats (soft, hard and rough) within one mesohabitat (Black Head), with the aim of determining the validity of our approach to habitat mapping of the continental shelf and its applicability at different spatial scales.

The first step in mapping continental shelf habitat was to confer with local fishers that had developed and recorded their own maps of the benthic habitat after working in the area for many years. Fishers "deal on a regular basis with a landscape that no one has seen" [22]. These maps were found to be accurate - specific features identified by the fishers were found in all instances that we looked for them. We found the precision with which features were recorded depended on their importance to the fishing operation. Obstructions or specific areas where stationary gear was targeted were recorded with higher precision than more general features that were of less direct impact to the fishing operation. As stated in the introduction, how we define habitat determines the questions we ask and the description that results.

Visual observation of acoustic echograms linked with GPS provided a good initial discrimination of habitat types. In the Black Head area three relatively distinct macrohabitats - nominally soft, hard and rough - were clearly discriminated. The success of this method should not be that surprising, given it is the technique used successfully by the fishers. Subsequent processing of digital data for the relatively simplistic indices of hardness and roughness [6] discriminated four habitat types, although we had no biological samples to confirm the fourth habitat type. Although RoxAnn can delineate six or seven "habitats" with different acoustic signatures, these "habitats" can not always be discriminated based on sediment type. In one instance only three sediment types could be delineated with certainty [16]. Given these studies and our own, it is clear that the full power of acoustic habitat discrimination has not been realised - there is far more information in the returning echoes and the pattern of echoes than is currently being interpreted. It appears that the main advantage of data interpretation systems such as the one developed for RoxAnn is that thcy provide a shorthand notation of gross habitat types that can be mapped and recalled for future reference. The data interpretation system provides no improvement over visual examination of the echogram and will be subject to unrecognised (and therefore uncorrected) physical and electrical noise, unless raw data are also examined. The depth dependency of the RoxAnn habitat indices in this particular instance illustrates the importance of first looking at the raw echogram and secondly of storing the digital data for post-processing.

Factors currently limiting the discriminatory capacity of acoustic habitat mapping are the technical performance, installation and platform for the acoustic system (including the capacity for digital data acquisition for mapping and subsequent reprocessing). More sophisticated data interpretation systems $[9,25]$ may improve habitat discrimination in the future, but this will depend on the dynamic range and sensitivity of the acoustic system, and utilising more of the information content of the echo returns, including multifrequency data. For example, there was generally a strong correlation between the indices of roughness and hardness (E1 and E2; figure 4), presumably because rough habitats are usually hard. However, in some instances (eg. gillnet sample in rough macrohabitat, table I; Kloser, unpublished data) hardness declines as roughness increases - as the substrate becomes rougher the acoustic signal is scattered to a greater extent and total reflected energy increases. In another instance - the finger reefs at the top of figure 5-gravel in gutters between reefs reflected more acoustic energy than the adjacent sediment-covered reef and appeared harder. Such physical properties of sound reflection need to be built into the data interpretation system, to more clearly distinguish signal from noise, and the biological significance of detected acoustic differences.

One aspect of seabed mapping with vertical beam acoustics that severely limits its applicability is its narrow footprint on the seabed. While this narrow footprint and the vertical beam make analysis of the returning echo for habitat characteristics more straightforward, coverage is much smaller than could be obtained with sidescan or multibeam systems. For areas of the shelf where variation in benthic habitat occurs over quite short distances, this small coverage limits the practicality of scientific surveys. A natural development of our approach is an industry-based "automated" surveys of a larger area with scientific verification of identified habitats.

Regardless of the acoustic system used, extensive groundtruthing is required. While fishers use the composition of their catches and damage to fishing gear to "train 
N. BAX et al.

Table III. Fish species that discriminate soft from rough macrohabitats in the Black Head and adjacent Disaster Bay mesohabitats. Percent dissimilarity, based on a SIMPER analysis, is the contribution of each species to the total between-macrohabitat dissimilarity.

\begin{tabular}{|c|c|c|c|c|}
\hline $\begin{array}{l}\text { Discriminating } \\
\text { (Common name) }\end{array}$ & $\begin{array}{c}\text { Species } \\
\text { (Scientific name) }\end{array}$ & $\begin{array}{l}\text { Average } \\
\text { relative } \\
\text { abundance } \\
\text { (soft) }\end{array}$ & $\begin{array}{c}\text { Average } \\
\text { relative } \\
\text { abundance } \\
\text { (rough) }\end{array}$ & $\begin{array}{l}\text { Percent } \\
\text { dissimilarity }\end{array}$ \\
\hline Gummy shark & Mustelus antarcticus & 4026 & 1220 & 4.8 \\
\hline Bastard trumpeter & Latridopsis forsteri & 30 & 469 & 3.9 \\
\hline Tiger flathead & Neoplatycephalus richardsoni & 176 & 0 & 3.5 \\
\hline Blue mackerel & Scomber australasicus & 363 & 34 & 3.3 \\
\hline Butterfly perch & Caesioptera lepidoptera & 3 & 171 & 3.2 \\
\hline Common sawshark & Pristiophorus cirratus & 174 & 12 & 3.1 \\
\hline Piked spurdog & Squalus megalops & 451 & 209 & 2.6 \\
\hline Red cod & Pseudophycis bachus & 123 & 0 & 2.6 \\
\hline Jack mackerel & Trachurus declivis & 1994 & 535 & 2.5 \\
\hline White trevally & Pseudocaranx dentex & 151 & 32 & 2.3 \\
\hline
\end{tabular}

themselves" in the interpretation of echograms, photographic records are indispensable in a scientific survey. Direct observation of macrohabitats by a towed video system was very useful in validating their biological significance. The use of the pitch-dampened towed video platform capable of being towed over all macrohabitats was essential to targeting video transects. Floating the video platform on a flexible chain (with weak links) provided a good technique to survey at a relatively constant height off even very rough bottom (where the weak links were broken several times with no damage to the video platform or cables). However, even with a towed system, the lack of steerage at the low speed $\left(1 \mathrm{~m} \mathrm{~s}^{-1}\right)$ necessary for observing the videos in real time compromised our ability to confine video transects to one macrohabitat at a time.

While acoustics provides an index of substrate type, this is only one of several important attributes of seafloor habitat that determine the distribution of invertebrates and fishes. Factors such as depth, proximity to topographic features, invertebrate community structure, level of disturbance and daylight also affect habitat use by marine invertebrates and fishes $[2,14,23,27,29]$. It is clear that sampling of the fish community must take place at several spatial and temporal scales if the importance of benthic habitat to fisheries production is to be determined from an ecosystem perspective. The use of particular benthic habitat types may be restricted to particular life history stages, season or modified by other environmental factors including presence of predators $[2,8,9,13]$. There are clear associations between fish community structure and mesohabitat distribution at Black Head shown by multispecies distributions and abundance, and dominant morphotypes. In the southeast Australian conti- nental shelf mesohabitat, associations may change with time: these may be diel movements, seasonal shifts or ontogenetic migrations and are often species-specific [20 and Williams, unpublished data].

Generally, site-specific differences in fish communities compound more general trends in fish distribution with depth [14]. Commcrcial fishcrs who sample far more frequently than scientific surveys report species-specific changes in availability on daily as well as seasonal timescales, and at local as well as broad spatial scales, often under the influence of large-scale oceanographic events. A sampling program aiming to assess the associations of fishes with habitat, and therefore habitat importance, needs to address such spatial and temporal seales of variability.

The associations of fishes with macrohabitat may be obligate or facultative. Obligate relationships are likely to be highly sensitive to structural changes in habitats. Impacts of structural changes in hahitat on facultative relationships are less clear, but the association of many taxa with structural habitat implies an increase in individual fitness that would be lost if the structural features were lost [1]. A facultative association of fishes with habitat, eg. for mobile or transient species, implies that spatial management by itself (at least at the scale reported here) may be insufficient for management of individual species. Additionally, the sizes of macrohabitat areas associated with fish distribution in this study were of a scale small enough that spatial management could prove inoperable at the level of individual macrohabitat patches. Spatial management by mesohabitat, or in conjunction with gear restriction (to direct effort towards particular macrohabitat types), may be more credible approaches. Successful 
management of individual species, the fish community and the ecosystem requires understanding the association of fish with habitat at the macrohabitat and mesohabitat level and its variability through time and ontogeny.

\section{CONCLUSION}

Commercial fishers' information was vital to delineating mesohabitats as the basis for our scientific survey and may be sufficient for many management purposes. Visual interpretation of vertical beam acoustic echograms discriminated three habitat types - soft, hard and roughwithin the Black Head mesohabitat. Post-processing of the echo returns using algorithms developed for the RoxAnn acoustic system did not provide substantial additional discriminatory power. Validation of habitat types discriminated by acoustics is essential and a towed photographic system was developed for this purpose. Habitat types discriminated by acoustics were found to have characteristic biota. The functional forms of invertebrates changed markedly between habitat types. The distinction between fish communities in different habitats was clear once confounding factors were accounted for.

Based on our current study we see the following elements as necessary for detailed benthic habitat mapping of the continental shelf for spatial management purposes:

- Synthesise industry knowledge of important areas;

- Real-time scientific acoustic survey to define habitats (save digital data);

- Redefine habitat boundaries based on ancillary data (photographic and invertebrates);

- Complete ancillary sampling of all habitats (eg. biota, sediments and hydrography);
- Reanalyse acoustic data with ancillary data to define ecologically important habitats;

- A natural development of this approach is an industrybased "automated" survey of larger area with scientific verification of identified habitats.

Depending on the specific questions to be addressed, the first three elements, or where industry knowledge is particularly reliable, even the first and third elements, may be sufficient to define habitat and its biological use for spatial management purposes.

\section{Acknowledgements}

It is a pleasure to acknowledge our many colleagues who have made this study possible. Invaluable information and advice was provided by several local fishers from Lakes Entrance (Victoria) and Eden (New South Wales). The fishing masters, captains, and crew of the FRV Southern Surveyor deserve special mention for working in often harsh conditions to deploy and retrieve sampling gear. 'l'he invertebrate sled was designed by Sebastian Rainer. Bruce Barker and Ian Helmond designed the towed video system. Matt Sherlock, Jeff Cordell and Lindsay MacDonald kept the scientific equipment functioning. Many CSIRO scientists and technicians and volunteers from other agencies, museums and students worked hard on the cruises to process and record the sam ples. Vicki Wadley, Tony Koslow and John Stevens edited and improved the manuscript. Alan Butler provided the French translations. The study was funded by CSIRO and the Fisheries Research and Development Corporation (Project 94-040).

\section{REFERENCES}

[1] Auster P.J., Malatesta R.J., Assessing the role of non-extractive reserves for enhancing harvested populations in temperate and boreal marine systems, in: Shackell N.L., Wilson J.H.M. (Eds.), Marine Protected Areas and Sustainable Fisheries, Science and Management of Protected Areas Association, Wolfville, Novia Scotia, Canada (1995), pp. 82-89.

[2] Auster P.J., Malatesta R.J., Donaldson C.L.S., Distributional responses to small-scale habitat variability by early juvenile silver hake, Merluccius bilinearis, Env. Biol. Fish. 50 (1997) 195-200.

[3] Barker B.A., Helmond I., Bax N., Williams A., Davenport S., Wadley, V.A., vessel-towed camera platform for sea-floor sur- veys of the continental shelf. Cont. Shelf Res. 19 (1999) 11611170 .

[4] Bcrnccker T., Partridge A.D., Wcbb J.A., Mid-late Tertiary deep-water temperate carbonate deposition, offshore Gippsland Basin, southeastern Australia, in: James N.P., Clarke J. (Eds.), Cool-water carbonates, SEPM Spec Pub 56, Tulsa, OK, USA, 1997, pp. 221-236.

[5] Caton A., McLoughlin K., Staples D. (Eds.), Fishery status reports 1997: Resources assessments of Australian Commonwealth fisheries, Bureau of Resource Sciences, Canberra, Australia, 1997, 139 p. 
[6] Chivers R.C., Emerson N., Burns D.R., New acoustic processing for underway surveying, Hydro. J. 56 (1990) 9-17

[7] Clarke K.R., Non-parametric multivariate analyses of changes in community structure, Aust. J. Ecology. 18 (1993) 117-143.

[8] Collie J.S., Escanero G.A., Valentine P.C., Effects of bottom fishing on the benthic megafauna of Georges Bank, Mar. Ecol. Prog. Ser. 155 (1997) 159-172.

[9] Collins W., Gregory R., Anderson J., A digital approach to seabed classification, Sea Tech., August (1996) 83-87.

[10] Dugan J.E., Davis G.E., Applications of marine refugia to coastal fisheries management, Can. J. Fish. Aquat. Sci. 50 (1993) 2029-2042.

[11] Edwards R.J., Upwelling could hold clues to fish patterns, Aust. Fish. 49 (1990) $18-20$.

[12] Fogarty M., Chaos, complexity and community management of fisheries: an appraisal, Mar. Policy 19 (1995) 437-444.

[13] Gotceitas V., Brown J.A., Substrate selection by juvenile Atlantic cod (Gadus morhua): cffects of predation risk, Occologia 93 (1993) 31-37.

[14] Gray C.A., Otway N.M., Spatial and temporal difference in assemblages of demersal fishes on the inner continental shelf off Sydney, south-eastern Australia, Aust. J. Mar. Freshwater Res. 45 (1994) 665-6/6.

[15] Greene H.G., Yoklavich M.M., Sullivan D., Cailliet G.M., A geophysical approach to classifying marine benthic habitats: Monterey Bay as a model, in: Applications of Side-Scan Sonar and Laser-Line Systems in Fisheries Research, Alaska Department Fish and Game, Juneau, Alaska, Spec. Pub. 9 (1995), pp. 15-30.

[16] Greenstreet S.P.R., Tuck I.D., Grewar G.N., Armstrong E., Reid D.G., Wright P.J., An assessment of the acoustic survey technique, RoxAnn, as a means of mapping seabed habitat, ICES J. Mar. Sci. 54 (1997) 939-959.

[17] Hilborn R., Gunderson D. R., Rejoinder: chaos and paradigms for fisheries management, Mar. Policy 20 (1996) 87-89.

[18] Hudson P.L., Griffiths R.W., Wheaton T.J., Review of habitat classification schemes appropriate to streams, rivers, and connecting channels in the Great Lakes drainage basin, in: Busch W.D.N., Sly P.G. (Eds.), The development of an aquatic habitat classification system for lakes, CRC Press, Ann Arbor, Michigan (1992), pp. 73-107.

[19] Kaiser M.J., Spencer B.E., The effects of beam-trawl disturbance on infaunal communities in different habitats, J. An. Ecol. 65 (1996) 348-358.

[20] Klaer N.L., Tilzey R.D.J., The multi-species structure of the fishery, in: Tilzey R.D.J. (Ed.), The South East Fishery, A scientific review with reference to quota management, Bureau of Resource Sciences, Canberra, Australia (1994), pp. 7294.

[21] Morrow R.A., Jones I.S.F., Sea floor drag coefficients - Eastern Bass Strait, University of Sydney, Ocean Sciences Institute, Report No. 29 (1988) 7 p.
[22] Neis B., Fisher's ecological knowledge and marine protected areas, in: Shackell N.L., Wilson J.H.M. (Eds.), Marine Protected Areas and Sustamable Fisheries, Science and Management of Protected Areas Association, Wolfville, Novia Scotia, Canada, 1995, pp. 265-272.

[23] Norcross B.L., Muter F.J., Holladay B.A., Habitat models for juvenile pleuronectids around Kodiak Island, Alaska, US Fish. Bull. 95 (1997) 504-520.

[24] Orlowski A., Application of multiple echoes energy measurements for evaluation of sea-bed type, Oceanologia 19 (1984) $61-78$.

[25] Prager B.T., Caughey D.A., Poeckert R.H., Bottom classification: Operational results from QTC View, MS presented at "OCEANS '95 - Challenges of Our Changing Global Environment" Conference, San Diego, California, USA, Questar Tangent, Marine Technology Centre, Sidney, B.C. Canada, $1995,9 \mathrm{p}$.

[26] Roberts C.M., Ecological advice for the global fisheries crisis, Trends Ecol. Evol. 12 (1997) 35-38.

[27] Roberts D.E., Davis A.R., Patterns in sponge (Porifera) assemblages on temperate coastal reefs off Sydney, Australia, Aust. J. Mar. Freshwater Res. 47 (1996) 897-906.

[28] Scwinghammer P., Guigne J-Y., Siu W.C., Quantifying the impact of trawling on benthic habitat using high resolution acoustics and chaos theory, Can. J. Fish Aquat. Sci. 53 (1996) 288-296.

[29] Thouzeau G., Robert G., Ugarte R., Faunal assemblages of benthic mega-invertebrates inhabiting sea scallop grounds from eastern Georges Bank, in relation to environmental factors, Mar. Ecol. Prog. Ser. 74 (1991) 61-82.

[30] Tilzey R.D.J., The South East Fishery - a scientific review with particular reference to quota management, Bureau of Resource Science, Canberra, Australia, 1994, 360 p.

[31] Tranter D.J., Carpenter D.J., Leech G.S., 'The coastal enrichment effect of the East Australian Current eddy field, DeepSea Res. 33 (1986) 1705-1728.

[32] Urick R.J., Principles of Underwater Sound, McGraw-Hill, New York, 1983, 423 p.

[33] Van Dolah R.F., Wendt P.H., Nicholson N., Effects of research trawls on hard-bottom assemblages of sponges and corals. Fish Res. 5 (1987) 39-54.

[34] Waring J.R., Kloser R.J., Pauly T., "Echo"- Managing Fisheries Acoustic Data, in: Proceedings of the International Conference on Underwater Acoustics, University of New Soulh Wales, December 1994, Australian Acoustical Society: Darlinghurst Public School, NSW, Australia, 1994, pp. 22-24.

[35] Wilson J.A., Acheson J.M., Metcalfe M., Kleban P., Chaos, complexity and community management of fisheries, Mar. Policy 18 (1994) 291-305. 